\title{
Neurological disability in leprosy: incidence and gender association in Sergipe, Brazil
}

\author{
Daniela Teles de Oliveira ${ }^{1}$, Marília Matos Bezerra ${ }^{2}$, José Antônio Pacheco de Almeida ${ }^{3}$, \\ Malcolm Duthie ${ }^{4}$, Steven Reed ${ }^{5}$, Amelia Ribeiro de Jesus ${ }^{6}$ \\ ${ }^{1}$ Laboratório de Biologia Molecular, Hospital Universitário, Departamento de Medicina, Universidade Federal \\ de Sergipe, Rua Claudio Batista s/n, Bairro Sanatório, Aracaju, Sergipe, Brazil, CEP 49060-100; ${ }^{2}$ Departamento \\ de Geografia, Universidade Federal de Sergipe, Cidade Universitária Prof. José Aloísio de Campos, Av. \\ Marechal Rondon, s/n Jardim Rosa Elze - CEP 49100-000 - São Cristóvão, Sergipe, Brazil; ${ }^{3}$ Departamento de \\ Geologia, Universidade Federal de Sergipe, Cidade Universitária Prof. José Aloísio de Campos. Av. Marechal \\ Rondon, s/n Jardim Rosa Elze - CEP 49100-000 - São Cristóvão, Sergipe, Brazil; Infectious Disease Research \\ Institute, Seattle, Washington, 98104, USA; IInstituto de Investigacão em Imunologia, Institutos Nacionais de \\ Ciência e Tecnologia, CNPq, São Paulo 05403-000, Brazil; ${ }^{6}$ Laboratório de Biologia Molecular, Hospital \\ Universitário Universidade Federal de Sergipe Rua Cláudio Batista, S/N. Bairro Sanatório, Aracaju, Sergipe, \\ Brazil, CEP: 49045-100
}

\begin{abstract}
Leprosy remains a public health problem in many countries. The disease affects skin and peripheral nerves and can cause irreversible disabilities. In Brazil, the detection rate of new cases is 18.2/100,000 inhabitants and leprosy control is considered a priority in the state of Sergipe. Studies showing the epidemiological profile and geographical distribution of leprosy cases are needed for effective epidemiological control measures. The objective of this study was to assess the detection rate of new cases, the geographical distribution and association with gender and clinical forms in Sergipe. Data were obtained from the Brazilian Institute of Geography and Statistics and the Information System for Notifiable Diseases. Maps indicating the geographical distribution of leprosy cases and the degree of neurological disabilities of all municipalities of the state were created using Spring, version 5.1.8 and ArcGIS, version 9.3.1. Hyper-endemic leprosy municipalities exist in Sergipe, indicating that the disease remains a major public health problem. The leprosy cases were found to be in municipalities with a higher number of dwellings with nine people per house. A detection rate of 33.0/100,000 inhabitants was noted in 2005, followed by a progressive reduction in the number of new cases until 2010. However, in the same period, an increase of cases with neurological disability was observed. A significant association of males with the multi-bacillary form and neurological disability was observed. This predisposition to severe forms of leprosy in males may be due to a delay in diagnosis and treatment emphasising the need for special attention by the leprosy control programme.
\end{abstract}

Keywords: Leprosy, epidemiology, neurological disability, Brazil.

\section{Introduction}

Leprosy is a chronic disease caused by infection with Mycobacterium leprae. The World Health Organization (WHO) puts the number of the worldwide registered cases of leprosy at 228,474 (WHO, 2010). In Brazil, the national incidence (here referred to as the new case detection rate) is 18.2 per 100,000

\footnotetext{
Corresponding author:

Amélia Maria Ribeiro de Jesus

Laboratório de Biologia Molecular

Hospital Universitário Universidade Federal de Sergipe

Rua Cláudio Batista, S/N. Bairro Sanatório, Aracaju, Sergipe, Brazil

CEP: 49045-100

Tel. +79 210 51806; Fax +79 21051811

E-mail: jesus-amelia@uol.com.br
}

inhabitants and within the state of Sergipe 18.4 per 100,000 inhabitants (WHO, 2010).

The cardinal signs of leprosy are skin lesions with altered sensation, thickened peripheral nerves and presence of alcohol/acid resistant (acid fast) bacilli in skin biopsies or lymph nodes. The bacteriological examination classifies patients either into the multi-bacillary (MB) or the pauci-bacillary (PB) form, while histopathological examination categorizes the disease as one of several clinical forms depending on the host immune response against the bacillus (van Brakel et al., 2008; Penna et al., 2008). Complications of leprosy include reactions and neurological disabilities. Patients can present neural inflammation and even permanent loss of sensory, autonomic and motor functions. In the absence of early intervention, sequelae responsible for strong social 
stigma and significant impairment of the quality of life appear (Scollard et al., 2006; Dias et al., 2007; Gomes et al., 2007; Schuring, 2008; Moschioni et al., 2010).

The WHO recommends a scale to classify the neurological disability caused by leprosy using grades attributed to eye, hand and foot as follows:

(i) grade 0 , no disability;

(ii) grade I, loss of sensibility in eyes, hands and/or feet at the level of $2 \mathrm{~g}$ of weight according to the monofilament test (Dros et al., 2009); and

(iii) grade II, lagophthalmos and/or ectropion, trichiasis or visual impairment with regard to sight and, with regard to hands and feet, visible damage such as "claw hand", "drop foot" or bone resorption in fingers or toes (Alves et al., 2010; Raposo et al., 2011).

No study characterizing the epidemiological profile of leprosy cases in Sergipe during the last five years has been published. Additionally, no previous study has tried to map the distribution of the disease, which is an impediment for the planning of epidemiological control measures.

The objective of this study was to produce maps showing the geographical distribution of new cases and the presence of neurological disability. We also wished to determine associations between gender with disease classification and neurological impairment as well as finding a possible link between leprosy and the population density expressed as the number of people per residence. To that end, a retrospective study in patients with confirmed diagnosis of leprosy for the years 2005 to 2010, analysing secondary data from the Brazilian government, was performed.

\section{Materials and methods}

During the five years between 2005 and 2010, the state of Sergipe had 3,039 leprosy cases, 240 (7.9\%) of these being under 15 years old. In 2005, the new case detection rate in the state was 33.0/100,000 inhabitants, with a progressive decrease in the following years, reaching 18.4/100,000 in 2010. In those under the age of 15 years, the incidence rates also decreased (from 10.0/100,000 in 2005 to 4.9/100,000 in 2010). All data related to leprosy were collected from the official database of the "Sistema de Informação de Agravos de Notificação" or SINAN (i.e. the information system for notification of diseases of compulsory notification). This system contains all confirmed cases in Sergipe based on all patients attended by the health services. Indicators of population development and population density were acquired from Instituto Brasileiro de Geografia e
Estatística or IBGE (i.e. the Brazilian Institute of Geography and Statistics). We assessed the differences between the number of houses with 3 people/house, 5 people/house and 9 people/house in the various municipalities in relation to the number of cases of leprosy reported using the Mann-Whitney test (a non-parametric, statistical hypothesis test for assessing whether one of two samples of independent observations tends to have larger values than the other) in GraphPad Prism, version 4.0 (http://www.graphpad.com/manuals/Prism4/ PrismUsersGuide.pdf).

The database was investigated by importing it into SPRING, version 5.1.8 (http://static.springsource.org/ spring-batch/reference/html/configureStep.html), while the ArcGIS, version 9.3.1 (http://wikis.esri.com/ wiki/display/ag93bsr/ArcGIS+Desktop) was used to construct maps showing the distribution of leprosy in the municipalities of Sergipe. The analyses were performed using GraphPad Prism, version 4.0. Mean, standard deviation and disease incidence were analysed in relation to the total population and in relation to the population under the age of 15 years.

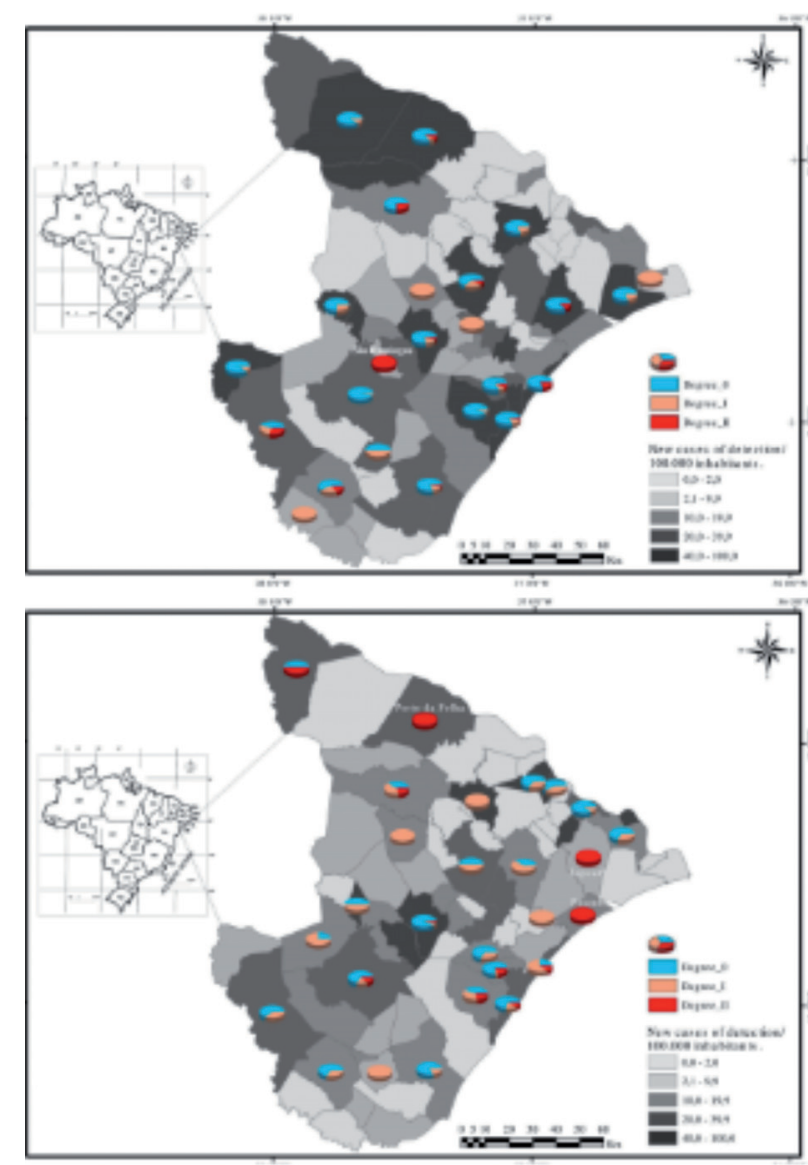

Fig. 1. Maps showing the localization of the state of Sergipe in the northeast corner of Brazil and the geographical distribution of new leprosy cases and the frequencies of neurological disabilities grades I and II in 2005 and in 2010. 


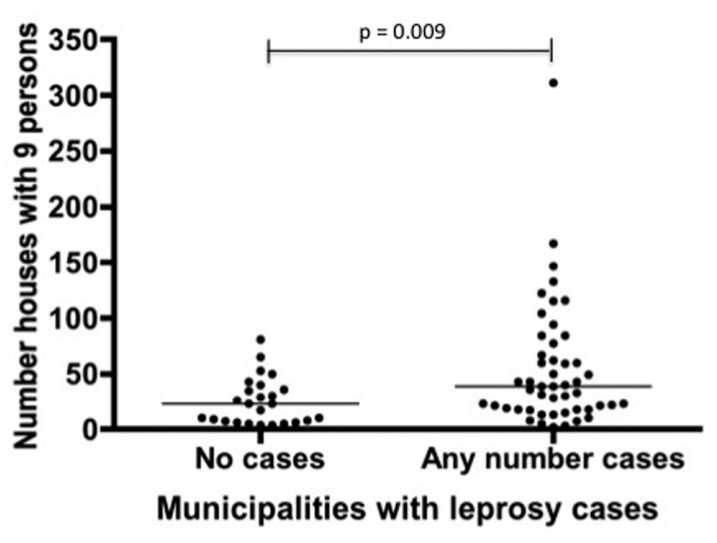

Fig. 2. The municipalities with leprosy cases presents higher numbers of houses with $\geq 9$ people/house. An outlier with 799 houses was excluded from the group of the municipalities with leprosy cases, but did not affect the statistical significance of the Mann-Whitney test $(\mathrm{P}=0.009)$.

Neurological disabilities and the gender distribution of $\mathrm{MB}$ and $\mathrm{PB}$ disease presentation were calculated. Associations between these variables were performed using a $\chi^{2}$ test with the Yates' correction.

\section{Results}

The geographical distribution of leprosy and the degree of the associated neurological disabilities in 2005 and 2010 in the 75 municipalities of Sergipe is shown in Fig. 1. Leprosy was documented in all regions of the state. Hyper-endemic incidence rates (> 40/100,000) were reported in 15 municipalities in 2005 , but reduced to eight municipalities in 2010. In 2005, neurological disabilities were detected in 24 municipalities, amounting to 68 cases with degree I, and 27 cases with degree II. Degree II of neurological disability, in which the patients present with limitations to daily activities, was observed in 12 municipalities. In 2010, neurological disabilities were detected in 27 municipalities, 70 cases with degree I, and 31 cases with degree II, the latter observed in 11 municipalities. After cure, neurological disabilities were still detected.
Analysing the association of leprosy new case detection rate with population indicators of development acquired from the IBGE, we did not find any correlation between the disease and income, educational and sanitation, but the number of households with 5 people/house $(\mathrm{P}=0.001)$ and 9 people/house $(\mathrm{P}=0.009$, Mann-Whitney test) were higher in the municipalities with leprosy cases, as compared to the ones with no leprosy cases (Fig. 2). No differences were observed when we analysed the numbers of houses with 3 people/house $(\mathrm{P}=0.13)$.

No gender predominance of leprosy in general was found in any of the years analyzed. However, when the bacteriological classification of the disease was considered in the total population (all ages), men were shown to be more affected by MB leprosy ( 854 cases), while PB forms (1,026 cases) were more common in women. In addition to the association of males with the $\mathrm{MB}$ form (OR 2.9, 95\% CI [2.46 to 3.30]; $\mathrm{P}<0.0001$ ), men were also associated with all degrees of neurological disability (OR 2.9, 95\% CI [2.29 to 3.56]; $\mathrm{P}<0.0001$ ), degree II as compared to degree 0 (OR 2.9, $95 \%$ CI [1.98 to 4.36]; $\mathrm{p}<0.0001$ ) or degree I as compared to degree 0 (OR $2.8,95 \%$ CI $[2.20$ to 3.64]; P <0.0001) (Table 1).

\section{Discussion}

Sergipe has a relatively high incidence of leprosy, and this situation remains a challenge for health professionals. The results analyzed from 2005 to 2010 indicate that the disease is still present though a progressive reduction in new cases was observed over the past five years.

The recent, lower incidence may be an indicator of reduced endemicity or, alternatively, of increased activity of leprosy control programs, including improved geographical coverage and increased awareness among the population in the endemic countries. (van Brakel et al., 2004; Mastrangelo et al., 2009). The decline observed in the present study can be explained by a reduction of cases due to a better quality of life

Table 1. Associations between gender, classification and degree of neurological disability.

\begin{tabular}{|c|c|c|c|c|c|c|c|}
\hline \multirow{2}{*}{ Variable } & \multicolumn{2}{|c|}{ Famale } & \multicolumn{2}{|c|}{ Male } & \multirow{2}{*}{ Odds ratio } & \multirow{2}{*}{$\begin{array}{c}95 \% \text { confidence } \\
\text { interval }\end{array}$} & \multirow{2}{*}{$\begin{array}{c}\chi^{2} \text { with } \\
\text { Yates' correction }\end{array}$} \\
\hline & $\mathrm{n} /$ total & $\%$ & $\mathrm{n} /$ total & $\%$ & & & \\
\hline Multibacillary & $497 / 1,596$ & 32.7 & $854 / 1,516$ & 56.3 & 2.9 & $2.46-3.30$ & $<0.0001$ \\
\hline Degrees I \& II $v s 0$ & $130 / 1,001$ & 13.0 & $372 / 1,289$ & 28.8 & 2.9 & $2.29-3.56$ & $<0.0001$ \\
\hline Degree II $v s 0$ & $35 / 1,001$ & 3.5 & $103 / 1,289$ & 8.0 & 2.9 & $1.98-4.36$ & $<0.0001$ \\
\hline Degree I vs 0 & $95 / 1,001$ & 9.5 & $269 / 1,289$ & 20.8 & 2.8 & $2.20-3.64$ & $<0.0001$ \\
\hline
\end{tabular}


and/or improvement of the environmental conditions associated with development of the disease or, more likely, it may represent a reduction in active case finding because, during the same period, we observed an increase of the degree II of neurological disability. Moreover, there is a maintenance of disease in those under 15 years of age, suggesting an early and continuous exposure to infection, since the incubation period is long (up to 10 years) (WHO, 2010).

The leprosy risk is increased in neighborhoods with previous reports of disease (Moet et al., 2004). Studies in highly endemic areas can identify other risk factors that contribute to the acquirement of leprosy, e.g. rural endemic settings with poor housing and sanitation conditions in substandard environments (Queiroz et al., 2010). In the present study, we observed that the municipalities with leprosy cases had comparatively more houses with high numbers of people per house, but no differences were observed when we analysed the numbers of houses with only three people per house, suggesting that an increased population density escalates the risk for acquiring leprosy.

In Sergipe there were no important differences in the total frequency of new cases in relation to gender. However, there was a clear predominance of $\mathrm{MB}$ forms of the disease in men for all years evaluated, with an association of the male gender with neurological disabilities as well. This association has also been observed in a preliminary analysis of retrospective data from a reference center in Aracaju, the capital of Sergipe (Simon et al., 2011).

Brazilian studies have reported a predominance of MB leprosy in men with a progressive increase during the last five years (Ministry of Health, 2010). This predisposition to more severe forms in the male gender may be related to factors such as initial infection load (Mastrangelo et al., 2009), social activities (Miranzi et al., 2010), neurological lesions (Deepak, 2003; Penna et al., 2008) or availability of medical care, all factors associated with increased susceptibility to mycobacterial infection (Teixeira et al., 2010) and higher frequency of leprosy reactions (Costa, 2002; Lana et al., 2003; Pavani et al., 2008).

The effect of gender as risk factor for intracellular infections is controversial. In leishmaniasis, both experimental animal investigations and epidemiological studies suggest a higher susceptibility in males (Mock and Nacy, 1998; Travi et al., 2002). The female gender has been described as a risk factor for extrapulmonary tuberculosis (GarcíaRodríguez et al., 2011), but another study shows a predominance of the male gender among infected patients (Baboolal et al., 2009). An experimental animal model of infection by Paracoccidioides braziliensis, a fungal infection, showed the influence of sex hormones on the immune response, demonstrating that testosterone promotes an increased production of IL-10 resulting in lowered protection against this infection (Pinzan, 2010). Although the predominance of males can be due to a higher exposure to infection, studies evaluating the effect of testosterone in susceptibility to leprosy would be needed for solving this question.

\section{Conclusions}

This documentation of the geographical distribution of leprosy per municipality in Sergipe, and the neurological disability due to this disease, sheds new light on the epidemiological situation. The 2005 to 2010 data on leprosy incidence indicate that the disease is currently decreasing in Sergipe. However, there are still hyper-endemic municipalities in the state and the frequency in children and young adolescents is stable, suggesting that the disease remains a major public health problem.

Neurological disability, observed in endemic municipalities during the same period, emphasises the impact of this disease on the quality of life in the population. The association between the male gender and MB leprosy and also neurological disability observed suggests that this category needs more attention from the leprosy control programme.

The findings of a higher risk for disability in men presented here should be useful for the planning of control measures concentrating efforts on special risk groups to detect and treat these cases as early as possible.

\section{Acknowledgement}

Financial support from CNPq Universal, Process $\mathrm{n}^{\circ}$ 477935/2009-5; ARJ is a Scientist from CNPq.

\section{References}

Alves CJMA, Barreto JA, Fogagnolo L, Contin LA, Nassif PW, 2010. Avaliação do grau de incapacidade dos pacientes com diagnóstico de hanseníase em serviço de dermatologia do Estado de São Paulo. Rev Soc Bras Med Trop 43, 460-461.

Baboolal S, Millet J, Akpaka PE, Ramoutar D, Rastogi N, 2009. First insight into Mycobacterium tuberculosis epidemiology and genetic diversity in Trinidad and Tobago. J Clin Microbiol 47, 1911-1914. 
Costa ALF, 2002. Hanseníase: incapacidades físicas após PQT, no período de 1994 a 1998 em Teresina-Piauí. In: 16 International Leprosy Congress. Salvador, Brazil.

Deepak S, 2003. Answering the rehabilitation needs of leprosy affected persons in integrated setting through primary health care services and community based rehabilitation. Indian J Lepr 75, 127-142.

Dias A, Cyrino EG, Lastotia JC, 2007. Knowledge and necessities of learning of physiotherapy's students about leprosy. Hansenol Int 32, 9-18.

Dros J, Wewerinke A, Bindels PG, van Weert HC, 2009. Accuracy of monofilament testing to diagnose peripheral neuropathy: a systematic review. Ann Fam Med 7, 555-558

García-Rodríguez JF, Álvarez-Díaz H, Lorenzo-García MV, Mariño-Callejo A, Fernández-Rial Á, Sesma-Sánchez P, 2011. Extrapulmonary tuberculosis: epidemiology and risk factors. Enferm Infec Microbiol Clin 29, 502-509.

Gomes FG, Frade MAC, Foss NT, 2007. Skin ulcers in leprosy: clinical and epidemiological characteristics of patients. An Bras Dermatol 82.

Lana CF, Lanza FM, Meléndez GV, Branco AC, Teixeira S, Malaquias LCC, 2003. Distribuição da hanseníase segundo sexo no Município de Governador Valadares, Minas Gerais, Brasil. Hansenol Int 28, 131-7.

Mastrangelo G, Scoizzato L, Fadda E, Silva GV, Santos LJ, Cegolon L, 2009. Epidemiological pattern of leprosy in an endemic area of North-East Brazil, 1996-2005. Rev Soc Bras Med Trop 42, 629-632.

Ministry of Health, 2010. Ministério da Saúde. Situação epidemiológica da Hanseniase no Brasil. Secretaria de Vigilância em Saúde, Brasília.

Miranzi SSC, Pereira LHM, Nunes AA, 2010. Perfil epidemiológico da hanseníase em um município brasileiro, no período de 2000 a 2006. Rev Soc Bras Med Trop 43, 62-67.

Mock BA, Nacy CA, 1988. Hormonal modulation of sex differences in resistance to Leishmania major systemic infections. Infect Immun 56, 3316-3319.

Moet FJ, Meima A, Oskam L, Richardus JH, 2004. Risk factors for the development of clinical leprosy among contacts, and their relevance for targeted interventions. Lepr Rev 75, 310-326.

Moschioni C, Antunes CMF, Grossi MA, 2010. Lambertucci JR. Risk factors for physical disability at diagnosis of 19,283 new cases of leprosy. Rev Soc Bras Med Trop 43, 19-22.

Pavani RAB, Tonolli ER, Avila SCGPD, 2008. Histopathological classification and clinical correlation of 50 leprosy c]ases from a teaching hospital, São José do Rio Preto, State São Paulo, Brazil. Medicina (Ribeirão Preto) 41, 188-195.
Penna GO, Pinheiro AP, Nogueira LSC, Carvalho LR, Oliveira MBB, Carreiro VP, 2008. Clinical and epidemiological study of leprosy cases in the University Hospital of Brasília: 20 years - 1985 to 2005. Rev Soc Bras Med Trop 41, 575-580.

Pinzan CF, Ruas LP, Casabona-Fortunato AS, Carvalho FC, Roque-Barreira MC, 2010. Immunological basis for the gender differences in murine Paracoccidioides brasiliensis infection. PLoS One 21, 5, e10757.

Queiroz JW, Dias GH, Nobre ML, Dias MCS, Araújo SF, Barbosa JD, Neto PB, Blackwell JM, Jeronimo SMB, 2010. Geographic information systems and applied spatial statistics are efficient tools to study Hansen's disease (leprosy) and to determine areas of greater risk of disease. Am J Trop Med Hyg 82, 306-314.

Raposo MT, Caminha AVQ, Heukelbach J, Sánchez-González MA, Medeiros JLA, Nemes MIB, 2011. Assessment of physical impairments in leprosy patients: a comparison between the World Health Organization (WHO) disability grade and the eye-hand-foot score. Rev Inst Med Trop São Paulo 53, 77-81.

Schuring RP, Richardus JH, Steyerberg EW, Pahan D, Faber WR, Oskam L, 2008. Preventing nerve function impairment in leprosy: validation and updating of a prediction rule. PLoS Negl Trop Dis 2, e283

Scollard DM, Adams LB, Gillis TP, Krahenbuhl JL, Truman RW, Williams DL, 2006. The continuing challenges of leprosy. Clin Microbiol Rev 19, 338-381.

Simon M, Scherlock J, Duthie MS, De Jesus AM, 2011. Clinical, immunological, and genetic aspects in leprosy. Drug Develop Res 72, 509-527.

Teixeira MAG, Silveira VM, França ER, 2010. Características epidemiológicas e clínicas das reações hansênicas em indivíduos paucibacilares e multibacilares, atendidos em dois centros de referência para hanseníase, na Cidade de Recife, Estado de Pernambuco. Rev Soc Bras Med Trop 43, 287-292. Travi BL, Osorio Y, Melby PC, Chandrasekar B, Arteaga L, Saravia NG, 2002. Gender is a major determinant of the clinical evolution and immune response in hamsters infected with Leishmania. Infect Immun 70, 2288-2296.

van Brakel WH, Lever P, Feenstra P, 2004. Monitoring the size of the leprosy problem: which epidemiological indicators should we use? Indian J Public Health 48, 5-16.

van Brakel WH, Nicholls PG, Wilder-Smith EP, Das L, Barkataki P, Lockwood DNJ, 2008. Early diagnosis of neuropathy in leprosy comparing diagnostic tests in a large prospective study (the INFIR Cohort Study). PLoS Negl Trop Dis 2, e212.

WHO, 2010. Wkly Epidemiol Rec 35, 332-348. 